\title{
DOCUMENTOS Y EVIDENCIA: \\ EL LUGAR DE LA GESTIÓN DOCUMENTAL EN LA LUCHA CONTRA LA CORRUPCIÓN
}

\author{
Gabriela Andaur \\ Profesora de Gestión de la Información, Bibliotecología y Archivística, Universidad Alberto Hurtado
}

\begin{abstract}
Resumen
En el presente artículo se discute acerca de la función que cumplen los documentos como evidencia del actuar de personas y organizaciones. Para ello, se utilizan ejemplos de la utilización de documentos en la investigación de casos recientes vinculados a la corrupción. Esta exposición tiene como finalidad poner de manifiesto la relevancia que puede tener este tipo de soporte de información en la prevención y esclarecimiento de estos casos, y con ello la necesidad de regular y mejorar la práctica de la gestión documental en Chile, especialmente en el ámbito de la administración pública.
\end{abstract}

Como reacción a la serie de casos de corrupción que han estado al centro del debate político nacional en los últimos meses, en febrero de este año fue anunciada la creación de un Consejo Asesor Presidencial, cuya misión fue proponer reformas que permitieran el control efectivo de conflictos de interés, tráfico de influencias y corrupción en la esfera pública. Una de las medidas propuestas por el Consejo es la realización de cambios en la regulación de archivos públicos y acceso a la información. Ante esto, cabe preguntarse qué relación existe entre la lucha contra la corrupción, los archivos y los documentos que estos custodian.

El presente artículo tiene por objeto abordar esta relación, desde la función que cumplen los documentos como evidencia del actuar de organizaciones y personas, utilizando para ello ejemplos extraídos de los casos Penta, SQM y Caval. En él se sostiene que la mejora de la gestión documental en la administración es una de las herramientas necesarias en la lucha contra la corrupción, al contribuir a la creación de documentos confiables que efectivamente sirvan de evidencia y que además permitan la rendición de cuentas de quienes participan en la administración del Estado.

\section{El documento como evidencia: ejemplos recientes}

En la visión tradicional de la gestión de información, el documento es entendido como el "subproducto" de actividades realizadas por personas e instituciones (Duranti \& Preston, 2008). El uso de este término alude a la naturalidad de la producción documental: la creación del documento no es un fin en sí mismo, sino un medio para la realización de un determinado acto o para dar cuenta de un suceso acontecido. La relación entre el documento y el acto que refleja o testimonia, así como el atributo de naturalidad mencionado, es lo que ha permitido -ya desde la Antigüedadafirmar la capacidad del documento de servir como evidencia del actuar de personas e instituciones. ${ }^{1}$

Aunque la noción del documento como medio de prueba aplica también en los ámbitos más cotidianos de nuestro quehacer, es en el contexto de investigaciones y procesos legales cuando puede observarse con mayor claridad. Como ejemplo, podemos observar el rol que ha tenido la documentación en las investigaciones realizadas en el marco del denominado caso Penta, la arista SQM, y el caso Caval. En estos casos, los documentos han permitido develar múltiples vínculos entre organismos y personas de los ámbitos público y privado, e investigar acusaciones de evasión tributaria, soborno, cohecho, lavado de activos, tráfico de influencias y uso de información privilegiada.

\section{Documentos y fraude: la falsa evidencia}

Como se ha dicho, una característica de todo documento es que es reflejo o producto de un determinado acto. No obstante, esta es una

(1) El documento se define como"información creada o recibida, conservada como información y prueba, por una organización o un individuo en el desarrollo de sus actividades o en virtud de sus obligaciones legales" (énfasis añadido) (AENOR, 2006). Esto se ha reforzado históricamente por la presunción de una relación el registro escrito y la verdad. Ver Heather Macneil, op. cit. 
característica ideal, pues la experiencia demuestra que la relación acto-documento puede ser alterada o falseada (Hurley, 2001).

Ejemplo de ello son los documentos que están al centro del caso Penta y la arista SQM: boletas y facturas ideológicamente falsas, falsas declaraciones de renta y contratos forward fuera de regla. Lo que está en discusión en estos casos no es la autenticidad de los documentos, sino la veracidad de los actos de los que dicen dar cuenta.

Desde el punto de vista de la gestión documental, en ellos se ha perdido la relación acto-documento. El documento no es un subproducto natural, sino que un producto creado deliberadamente para dar testimonio de una situación irreal (la generación de pérdidas en una empresa, en el caso de las declaraciones de renta falsas), o de hechos nunca ocurridos (la prestación de un servicio, en el caso de las boletas). En el caso de los contratos forward, los documentos se utilizaban para dar falsa cuenta de la celebración de acuerdos entre dos partes: las fechas de los contratos eran adulteradas, lo que le permitía a los involucrados -siempre grandes contribuyentes- simular pérdidas para, en última instancia, evadir impuestos (Ramírez, 2015).

De probarse las acusaciones en estos casos, veríamos en ellos la explotación del carácter evidencial del documento en un sentido malicioso, con el fin de producir engaño. Este no es un hecho nuevo, pues hay quienes han puesto de manifiesto las múltiples mediaciones que pueden operar en la creación y gestión de documentos por parte de actores con motivaciones e intereses divergentes (Lemieux, 2001). Esto nos obliga a tomar con precaución la relación acto-documento y, más aún, la relación entre la verdad de los hechos y lo documentado. Pero hay otros casos en lo que esta relación sí se hace visible.

\section{Documentos y verdad: el rastro involuntario}

En circunstancias normales, es decir, cuando no media la intención de producir engaño, es posible asumir que la relación entre acto y documento existe. En estos casos el documento se erige como instrumento probatorio y testimonia la ocurrencia de actos o hechos ocurridos -función que tradicionalmente cumple la evidencia en un contexto legal.

En este sentido, podemos mencionar el rol que ha tenido la revelación de correos electrónicos en los casos Penta y SQM. Un buen ejemplo es la ya célebre serie de comunicaciones enviadas por políticos de diversos sectores a ejecutivos de Penta para solicitar aportes para campañas electorales, correos que han sido uno de los principales medios de prueba para determinar el propósito por el cual las falsas boletas y facturas mencionadas en el apartado anterior fueron emitidas en primer término. En este caso, los correos electrónicos son el subproducto de una acción concreta -la solicitud irregular de recursos- y por lo mismo dan testimonio de las mismas. A su vez, las boletas que antes fueran evidencia falseada de servicios no prestados, se transforman en evidencia de aportes irregulares realizados por empresas a campañas electorales.

En esta y otras situaciones, la seguidilla de boletas emitidas por una u otra parte han permitido avanzar, de forma paulatina, en el esclarecimiento de redes establecidas entre políticos, operadores y empresas: las boletas emitidas a Penta por el ex subsecretario Pablo Wagner han servido al SII para establecer una querella contra sus ejecutivos Jorge Délano y Carlos Eugenio Lavín por soborno; las boletas emitidas a Asesorías y Negocios, empresa de Giorgio Martelli, por colaboradores de la Nueva Mayoría, y los registros de pagos irregulares de SQM Salar a dicha empresa, han permitido avanzar en el esclarecimiento de los mecanismos de financiamiento de la presunta pre-campaña presidencial. En estos casos, que son sólo un par de los muchos que han surgido en la investigación, el documento reafirma su carácter de evidencia, como sedimento o rastro involuntario de actos, transformándose en medio para el esclarecimiento de la verdad.

Por último, el caso Caval, de naturaleza distinta a los ya mencionados, permite ilustrar otra característica del documento. En este caso, en el que se investiga posible tráfico de influencias y uso de información privilegiada, se han presentado como medios de prueba correos electrónicos entre el Director de Obras de la Municipalidad de Machalí y la empresa Caval Ltda. Estos correos contendrían información relativa a una propuesta de modificación de uso de suelos en la comuna, información privilegiada a utilizar en un negocio inmobiliario de Caval. El documento -correo electrónico- es medio de prueba del intercambio de información, pero es además un ejemplo claro de un hecho fundamental que a veces se olvida: el documento es, ante todo, un soporte de información, y dicha información puede ser utilizada con fines diversos, dentro o fuera del marco de lo ético, lo legítimo y lo legal.

\section{El rol de la gestión documental}

Ya sea que el documento se utilice como medio para el engaño o como evidencia, es portador de información, y es la necesidad de resguardar y preservar la información que contiene el documento lo que explica que exista una disciplina como la gestión documental. La relación entre ésta y la corrupción no es, a primera vista, la más evidente, pero sí se puede sostener que "una gestión documental deficiente es a menudo un barómetro de una deficiente administración de los asuntos" (Eastwood, 2012). 
Aunque no es un antídoto o fórmula mágica que pueda siempre evitar los usos o mal usos del documento, sí permite asegurar la existencia y disponibilidad de los rastros que estos dejan.

En esta línea, existen casos ejemplares vinculados al fraude y corrupción que han detonado cambios significativos en las formas de gestionar y preservar documentos, de los cuales el más notable en el ámbito internacional, es el caso Enron². Cuando estalló este caso -en el que la compañía estadounidense alteró reiteradamente sus estados financieros, ocultando su déficit para aumentar el valor de sus acciones- el debate se centró en la creación de mecanismos necesarios para evitar fraudes contables y proteger a los inversores, los que fueron finalmente estipulados en una ley a la que se bautizó como Sarbanes-Oxley (2002).

No obstante, el rol que cumplió en el caso la compañía auditora Arthur Andersen, que destruyó masivamente documentos para ocultar evidencia, generó también una reacción de los profesionales de la gestión documental en Estados Unidos. Como resultado, en el año 2004 se publicaron los Principios de Sedona, documento que contiene 14 principios que regulan las responsabilidades de organismos públicos y privados en la preservación y puesta a disposición de documentación electrónica que sea susceptible de ser utilizada en litigios (The Sedona Conference, 2007).

Como señalara un reconocido defensor del rol de los archivos en las sociedades democráticas, el caso Enron no solo deja una moraleja sobre los peligros del poder corporativo fuera de control, sino que también demuestra cómo este tipo de eventos pueden impulsar el establecimiento de estándares profesionales de gestión documental (Jimmerson, 2010).

\section{La lección por aprender}

Como se mencionó en un comienzo, en Chile la reacción oficial fue la creación del Consejo Asesor Presidencial contra los conflictos de interés, el tráfico de influencias y la corrupción. En el producto final de la Comisión, el denominado Informe Engel, en el área Prevención de la Corrupción se propone una medida que atañe directamente a la gestión documental: "se recomienda modificar la legislación en materia de archivos, estableciendo obligaciones, plazos y procedimientos para asegurar el buen resguardo de los archivos públicos y los mecanismos eficaces para el acceso a la información" (Consejo Asesor Presidencial, 2015).

Teniendo Chile una ley de archivos que data de 1929 (DFL 5.200), el debate entre profesionales de la gestión documental sobre la necesidad de modificar la normativa en materia de archivos públicos no es nuevo. En este sentido, existen expectativas respecto a posibles cambios, aunque en el presente no existe información sobre si la propuesta de la Comisión se materializará, ni de la manera en que lo hará.

De realizarse, la modificación de la legislación debiera, además de estipular las obligaciones, plazos y procedimientos relativos al resguardo de los documentos, avanzar hacia la regulación y protección de los mismos, desde el momento de su creación y a lo largo de toda su gestión. Sólo de esta manera se fortalecerá la capacidad de la administración de asegurar la autenticidad, confiabilidad, integridad y usabilidad de los documentos que genera y transmite, advertir su utilización indebida y garantizar su capacidad de servir como evidencia.

Aprender la lección que dejan las recientes experiencias de corrupción debe implicar la regulación de prácticas para la gestión documental en las organizaciones, especialmente en el sector público, y el establecimiento de principios éticos que apliquen en este campo, con el fin de proveer a cualquier organismo de medios para el establecimiento de juicios informados sobre las acciones de personas e instituciones.

El valor de la mejora en la gestión documental debiera, además, valorarse como herramienta indispensable para la transparencia y la rendición de cuentas ante la ciudadanía, cuyo ejercicio se juzga necesario en toda sociedad que se diga democrática.

\section{Bibliografía}

AENOR. (2006). UNE-ISO 15489-1. Información y Documentación Gestión de Documentos - Parte l: Generalidades. Madrid: AENOR. Baeza, A. (25 de 2 de 2015). Caso Caval: Fiscalía de O'Higgins incauta documentos y planos desde Municipalidad de Machalí. La Tercera. Obtenido de http://www.latercera.com/ noticia/nacional/2015/02/680-618278-9-caso-caval-fiscalia-de-ohiggins-incauta-documentos-y-planos-desde-municipalidad.shtml

Carmona, A., \& Macarena, S. (17 de 4 de 2015). Fiscalía incautó información contable de SQM Salar, filial donde se encontraban las facturas de Giorgio Martelli. El Mostrador. Obtenido de http://www.elmostrador.cl/noticias/pais/2015/04/17/ fiscalia-incauto-informacion-contable-de-sqm-salar-filial-donde-se-encontraban-las-facturas-de-giorgio-martelli/ Consejo Asesor Presidencial contra los Conflictos de Interés, el

(2) Para una síntesis del caso Enron y sus implicancias éticas, legales y corporativas, ver Tonge, A., Greer L. y Lawton, A. (2003) 
Tráfico de Influencias y la Corrupción. (2015). Informe Final. Obtenido de http://consejoanticorrupcion.cl/informe

Duranti, L., \& Preston, R. (2008). International Research on Permanent Authentic Records in Electronic Systems. Experiencial, Interactive and Dynamic Records. Padua: Associazione Nazionale Archivistica Italiana.

Eastwood, T. (2012). Archives, Democratic Accountability, and Truth. En C. Avery, \& M. Holmlund, Better off Forgetting? Essays on archives, public policy, and collective memory (págs. 143168). Toronto: University of Toronto Press.

Faúndez, G., Miranda , F., \& Siredey, F. (1 de 4 de 2015). Los correos políticos que la fiscalía incautó al grupo Penta. La Tercera. Obtenido de http://www.latercera.com/noticia/politica/2015/01/674-611132-9-los-correos-politicos-que-lafiscalia-incauto-al-grupo-penta.shtml

González, M., \& Ramírez, P. (9 de 1 de 2015). Querella del SII contra ex subsecretario Wagner incluye sociedad del presidente de la UDI. CIPER. Centro de Investigación periodística.

Hurley, C. (2001). The Evolving Role of Government Archives in Democratic Societies. ACA Annual Conference. Winnipeg. Obtenido de http://www.infotech.monash.edu.au/research/ groups/rcrg/publications/ch-demo0603.pdf
Jimmerson, R. (2010). Archives, Memory, Accountability and Social Justice. Chicago: SAA

Lemieux, V. (2001). Let the Ghosts Speak: An Empirical Exploration of the "Nature" of the Record. Archivaria, 81-111.

Macneil, H. (2001). Trusting Records in a Postmodern World. Archivaria, 36-47.

Ministerio Secretaría General de la Presidencia. Decreto №002. Crea Consejo Asesor Presidencial contra los conflictos de interés, el trafico de influecnias y la corrupción (2015)

Ramírez, P. (25 de 03 de 2015). Contratos forward: así se rompió el secreto de la mayor fórmula de evasión tributaria de Penta. Obtenido de CIPER. Centro de Investgación Periodística: http:// ciperchile.cl/2015/03/25/contratos-forward-asi-se-rompio-elsecreto-de-la-mayor-formula-de-evasion-tributaria-de-penta/

Sarbanes-Oxley Act of 2002, Pub. L. No. 107-204, 116 Stat. 745 (30 de julio de 2002)

The Sedona Conference. (2007). The Sedona Principles: Second Edition. Best Practices Recommendations \& Principles for Addressing Electronic Document Production. Obtenido de: https://thesedonaconference.org/download-pub/81

The Enron Story: You Can Fool Some of the People Some of the Time, Business Ethics: A European Review 12(1), 4-22. DOI: $10.1111 / 1467-8608.00301$ 